\title{
Use of Lasers in the Management of Mucocele: Two Case Reports
}

\author{
Vidyaa Hari Iyer, Vijayalakshmi Moorthy, Padmapriya Ramalingam
}

\begin{abstract}
A mucous cyst (mucocele, mucous retention cyst, ranula, epulis) is a painless, thin sac on the inner surface of the lips. It contains clear fluid. They are painless but can be bothersome. The cysts are thought to be caused because of sucking of the lip membranes between the teeth. Mucous cysts are common and harmless. However, if left untreated, they can organize and form a permanent bump on the inner surface of the lip. They are called ranula when on the floor of the mouth, and epulis when on the gums. The sac may be formed around the jewellery (piercings) that have been inserted into the lips or tongue. This article highlights the use of lasers in the treatment of excision of mucocele.
\end{abstract}

Keywords: Mucocele, Diode laser, Erbium laser, Excision, Minimal bleeding.

How to cite this article: lyer $\mathrm{VH}$, Moorthy $\mathrm{V}$, Ramalingam $\mathrm{P}$. Use of Lasers in the Management of Mucocele: Two Case Reports. Int J Laser Dent 2012;2(3):92-96.

Source of support: Nil

Conflict of interest: None declared

\section{INTRODUCTION}

A mucous cyst of the oral mucosa, also known as a 'mucocele' is a clinical term that refers to two related phenomena: mucous extravasation phenomenon and mucous retention cyst. It is a swelling of the connective tissue consisting of collected mucin due to a ruptured salivary gland duct usually caused by local trauma. A mucous cyst is a painless, thin sac on the inner surface of the lips. It is painless but bothersome. The sac can also occur on the tongue, palate, inside the cheeks, the floor of the mouth or around tongue or lip piercings. A mucous cyst often can be left alone; it usually will rupture spontaneously. There is no known prevention, but one could avoid intentionally sucking the cheeks or lips between the teeth. The mucocele ${ }^{1}$ has a bluish translucent color, and is more commonly found in children and young adults. When found on the floor of the mouth; the mucocele is referred to as a ranula. They are rarely found on the upper lip. The size of oral mucoceles varies from $1 \mathrm{~mm}$ to several centimeters. On palpation, mucoceles may appear fluctuant but can also be firm. Their duration lasts from days to years and may have recurrent swelling with occasional rupturing of its contents. A variant of a mucocele is found on the palate, retromolar pad and posterior buccal mucosa known as a 'superficial mucocele', this type presents as single or multiple vesicles and bursts into an ulcer. Despite healing after a few days, superficial mucoceles recur often in the same location. Mucoceles tend to relapse and is the second most frequent benign soft tissue tumor of the oral cavity following irritational fibroma.

Microscopically, mucoceles appears as granulation tissue surrounding mucin. Since, inflammation occurs concurrently, neutrophils and foamy histiocytes usually are present. Some mucoceles spontaneously resolve by themselves after a short time. Others are chronic and require surgical removal. Recurrence may occur, and thus the adjacent salivary gland is excised ${ }^{2}$ as a preventive measure. Several types of procedures are available for the surgical removal of mucoceles. These include laser and minimally invasive techniques which means recovery time is reduced drastically. A non-surgical option that may be effective for a small or newly identified mucocele is to rinse the mouth thoroughly with salt water four to six times a day for a few days. This may draw out the fluid trapped underneath the skin without further damaging the surrounding tissue.

\section{CASE REPORTS}

This article discusses two cases done under erbium and diode laser to excise the mucocele from the inner surface of the lower lip.

\section{Case 1}

A 38-year-old female patient had come to our clinic with complaints of a swelling in the lower lip which was growing in size in the left commissural region for the past 1 month (Figs 1 and 2). On clinical examination the patient revealed that she had a habit of biting her lips and hence this swelling. The swelling was fluctuant but painless. The swelling was $1 \times 1 \mathrm{~cm}$ in size and around $1 \mathrm{~cm}$ in width. The patient was explained that the lesion had to be excised with the use of lasers, which was the latest option available. The patient had given consent for laser excision. A $940 \mathrm{~nm}$ diode laser (Ezlase, Biolase, USA) was used to excise the lesion (Fig. 3). The settings used was $1 \mathrm{~W}$, continuous mode using a $400 \mu \mathrm{m}$ initiated tip in contact mode (Fig. 4). The incision was made on the top of the swelling and the lesion was excised slowly (Figs 5 and 7) with the capsule intact. The lesion (Fig. 6) was further sent for histopathological investigation. The histopathological study confirmed the lesion to be mucocele. The patient was recalled for 1 week postoperative checkup (Fig. 8). 


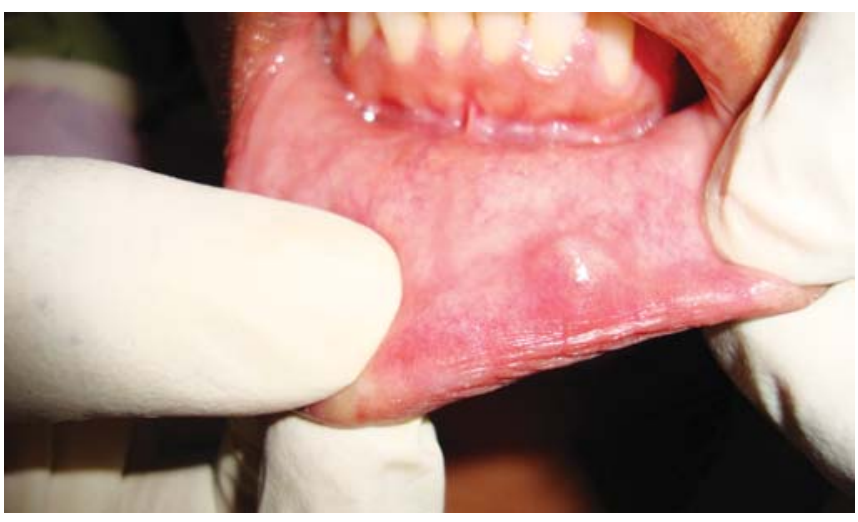

Fig. 1: Preoperative view of the lesion in the lower lip (case 1)

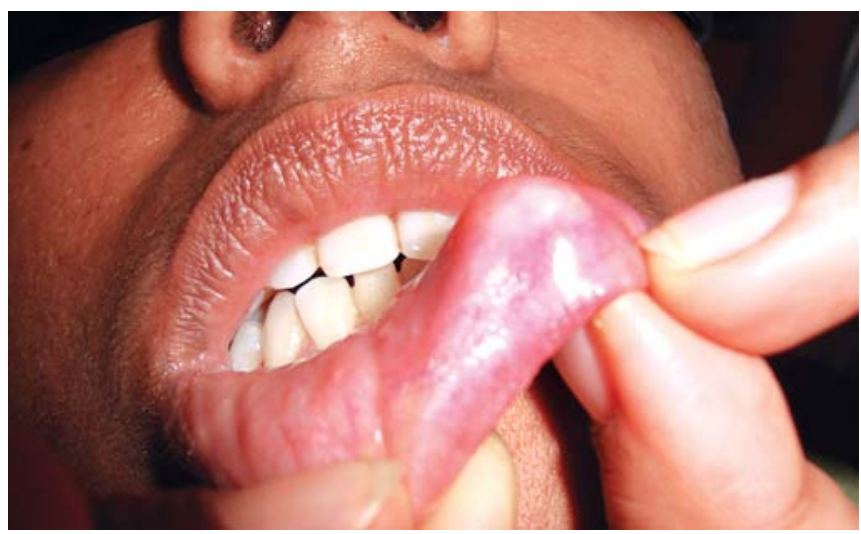

Fig. 2: Everted lip showing the prominence of the lesion (case 1)

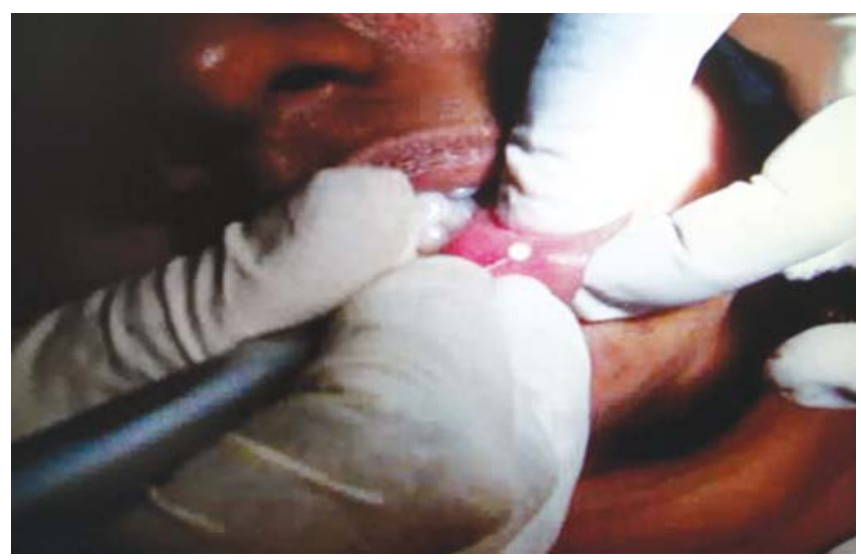

Fig. 3: Lesion excision done using diode $400 \mu \mathrm{m}$ initiated tip (case 1)

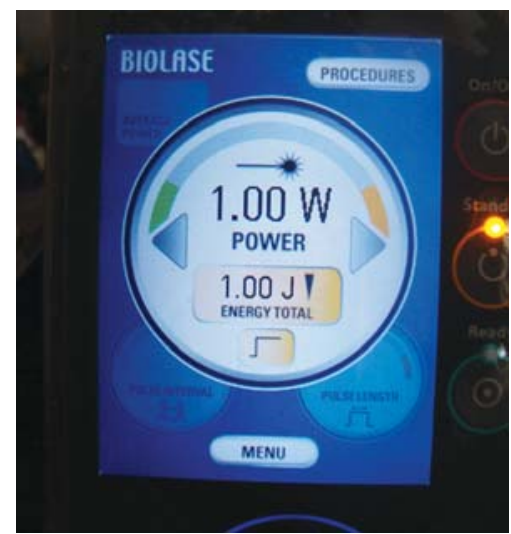

Fig. 4: Laser settings (Diode, Ezlase, Biolase, USA) (case 1)

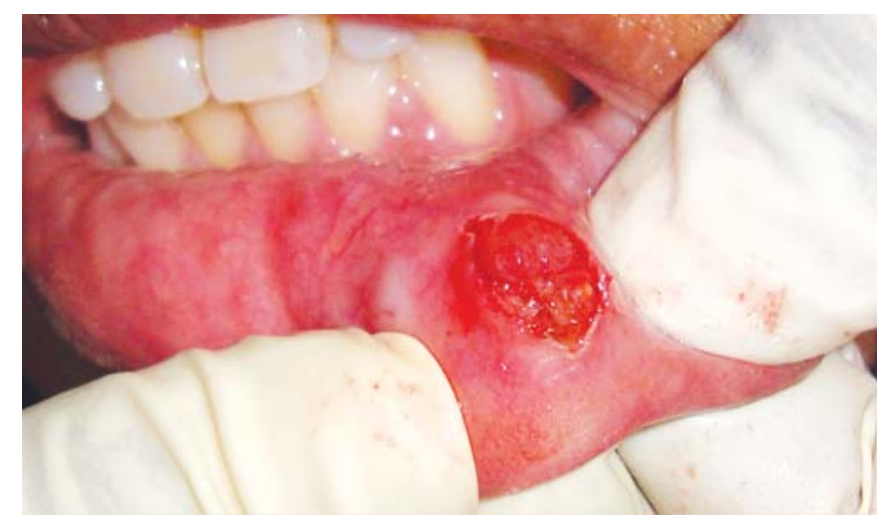

Fig. 5: The exposed lesion (case 1)

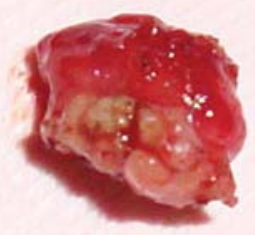

Fig. 6: Excised lesion (case 1)

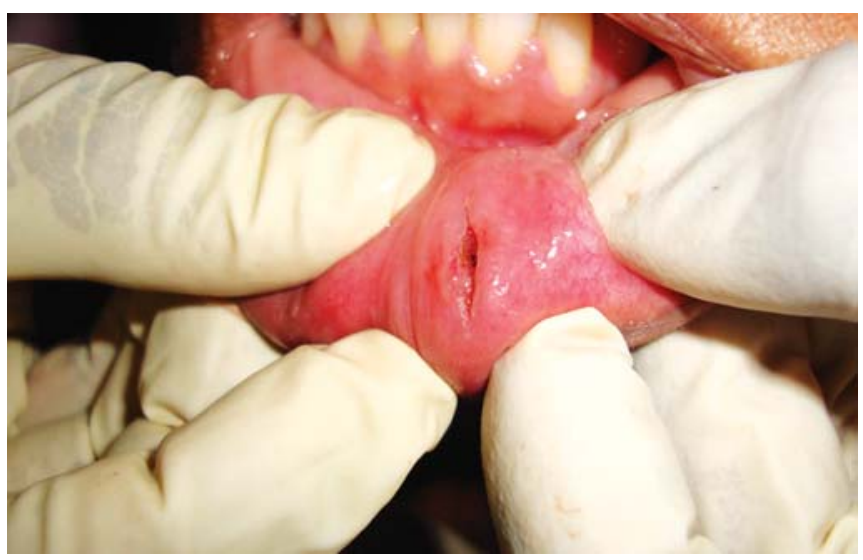

Fig. 7: Immediate postoperative view (case 1)

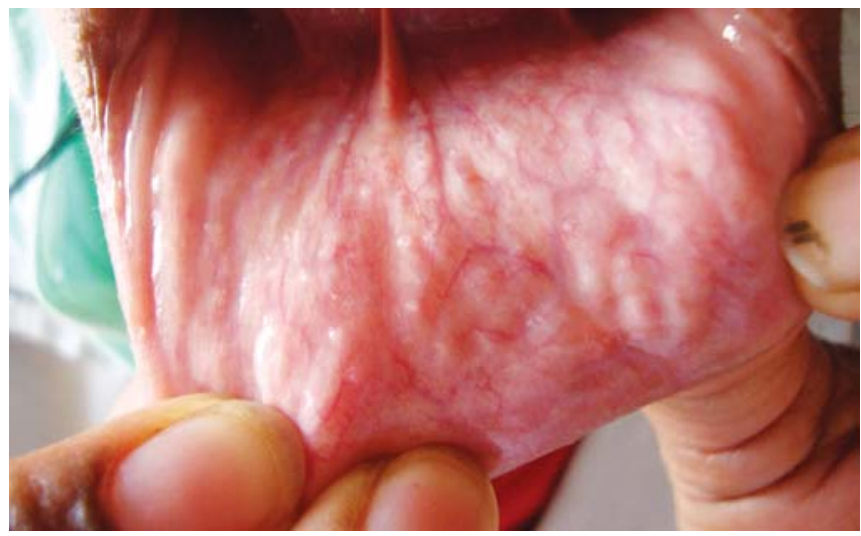

Fig. 8: One-week postoperative view (case 1) 


\section{Case 2}

A 16-year-old female patient visited the clinic with a swelling in the lower lip in the right commissural region since 1 week (Figs 9 and 10). On clinical examination the patient revealed that she had a habit of biting her lips and hence this swelling. She was concerned as the swelling had grown over the last 3 days which was hindering her speech. The swelling was fluctuant and painless. The swelling was $1.5 \times 1 \mathrm{~cm}$ in size and around $1 \mathrm{~cm}$ in width. The patient

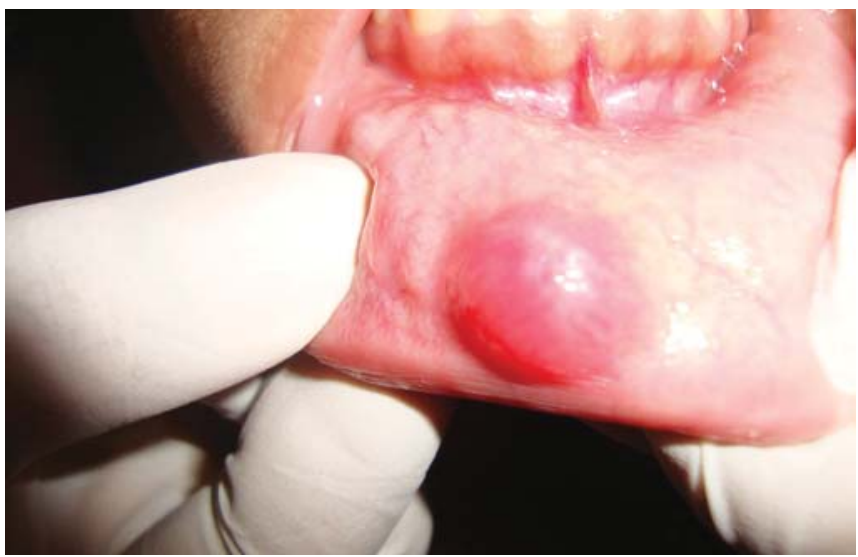

Fig. 9: Preoperative view of the lesion at the commissure of the left buccal mucosa (case 2)

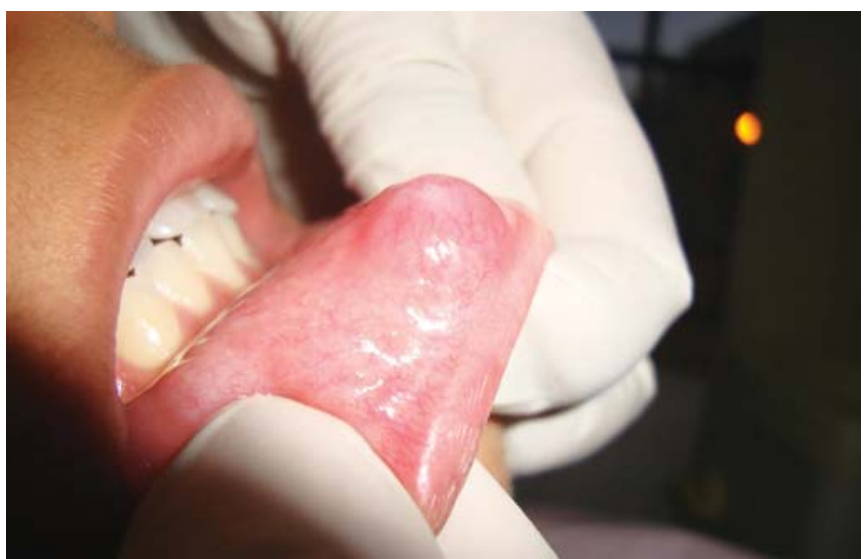

Fig. 10: Everted lip showing the prominence of the lesion (case 2)

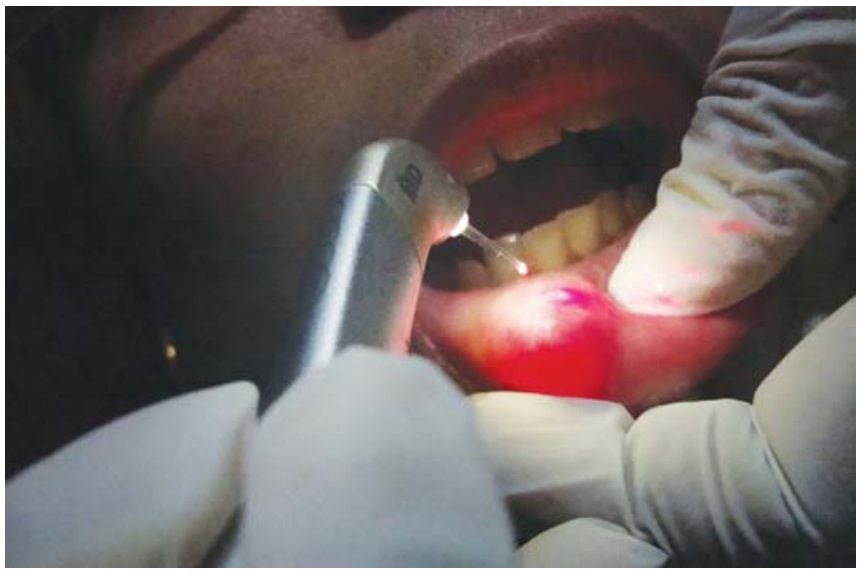

Fig. 11: Er,Cr:YSGG laser with sapphire tip (case 2) was explained that the lesion had to be excised and a latest option available was with use of lasers. The patient had given consent for laser excision. A 2,780 nm erbium laser (Er,Cr:YSGG, Waterlase, Biolase, USA) was used to excise the lesion. ${ }^{3}$ The settings used were $1.75 \mathrm{~W}, \mathrm{~S}$ mode, $40 \mathrm{~Hz}$, $11 \%$ air and $8 \%$ water with a sapphire tip in contact mode (Figs 11 and 12). The incision was made on the top of the swelling and the lesion was excised slowly (Figs 13 and 14). The lesion (Fig. 15) was further sent for histopathological

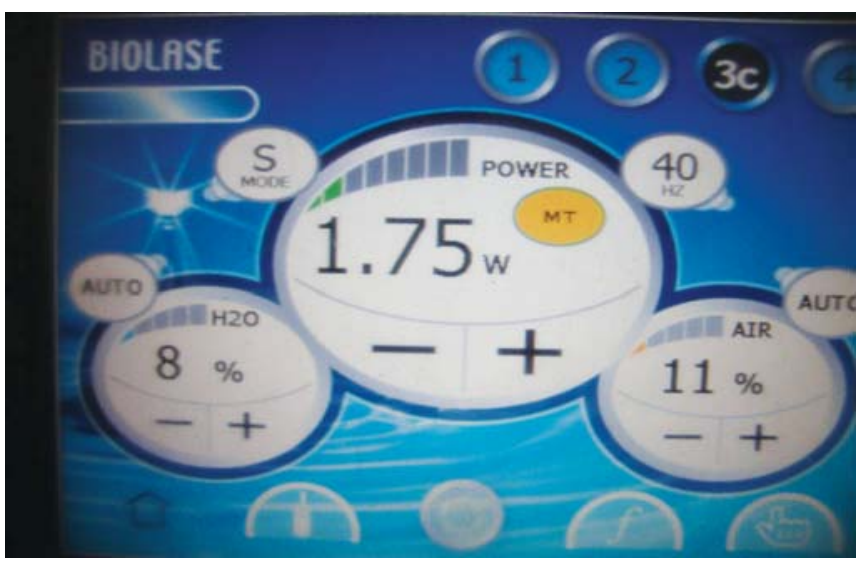

Fig. 12: Laser settings (case 2)

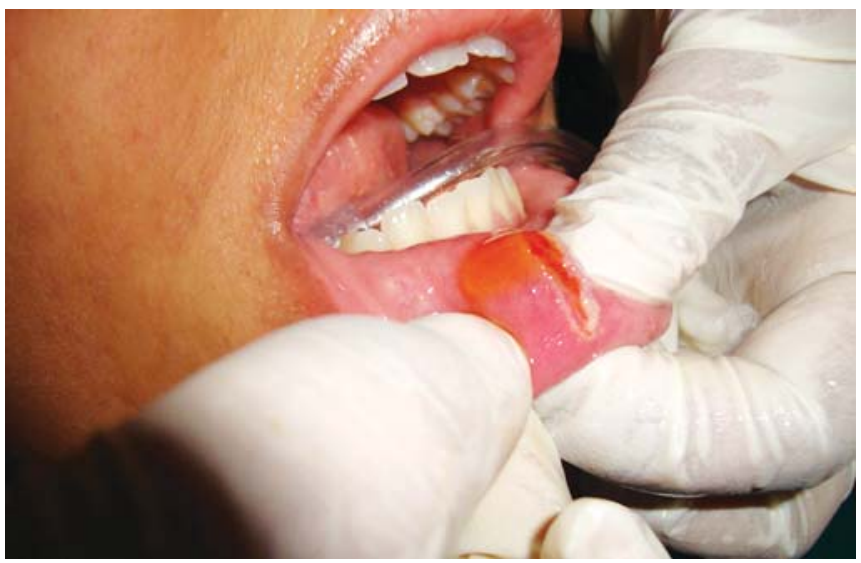

Fig. 13: Intraoperative view using laser (case 2)

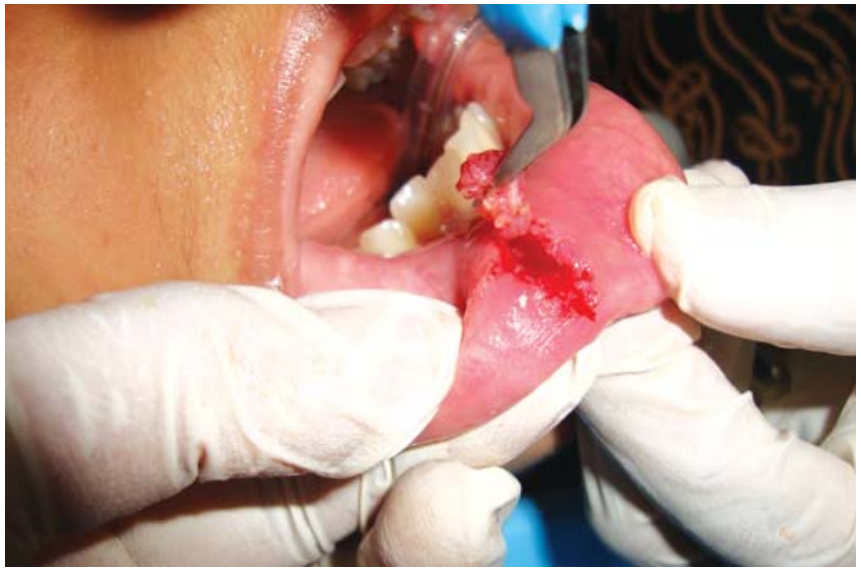

Fig. 14: Exposed lesion (case 2) 
investigation. The histopathological studies confirmed the lesion to be mucocele. The enucleated area was further approximated and low level laser therapy was done (Figs 16 and 17). The patient was recalled after 1 day for a checkup (Fig. 18).

The two patients had no systemic diseases and had complete dentition with good oral hygiene. The lip was everted with digital pressure to increase the lesions' prominence during surgical excision. All laser safety protocols were followed prior to and during the laser surgical procedure. Enameloplasty was carried out on all the sharp teeth to prevent the same problem in near future. Postoperative instructions were given to the patient to stop the habit of lip biting.

\section{DISCUSSION}

Mucoceles or retention cysts are based on inflammatoryirritative genesis. Total elimination is aimed for not only cystostomy but also to prevent recurrence. The erbium

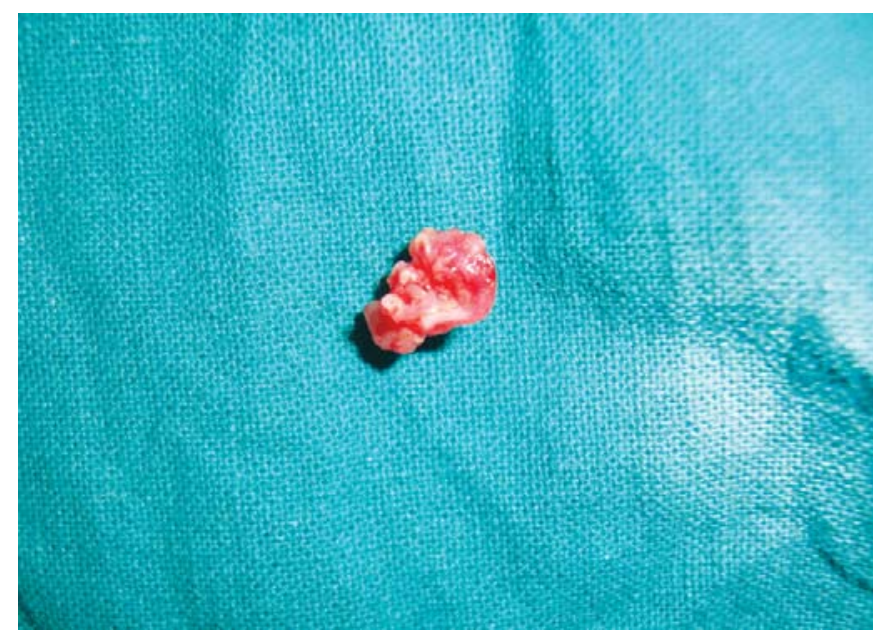

Fig. 15: Excised lesion (case 2)

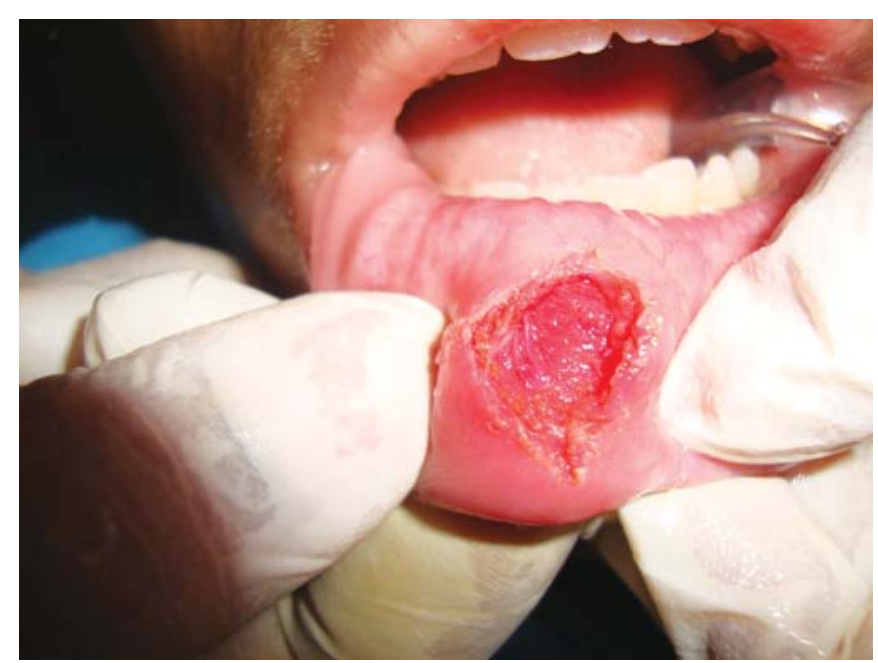

Fig. 16: Enucleated region (case 2)
(Er,Cr:YSGG) laser which is well absorbed by water, enables it to be used on oral soft tissue without causing thermal damage. Dental lasers provide an easy and comfortable option of keeping the procedure efficacious as well as minimally invasive. The quicker and uneventful healing after laser therapy adds to patient satisfaction. The tentative diagnosis of a mucocele is made from the clinical history, clinical presentation and palpation of the lesion and the definitive diagnosis is made by histopathology. The histopathological report confirmed the presurgical diagnosis in both the cases.

\section{CONCLUSION}

The usage of lasers in the treatment of mucocele proved to be a comfortable procedure for the doctor as well as the patient. The patients were able to resume to their daily work and hence found this treatment modality as a welcome alternative to conventional scalpel treatment with suture placement. Lasers have made surgical dentistry more

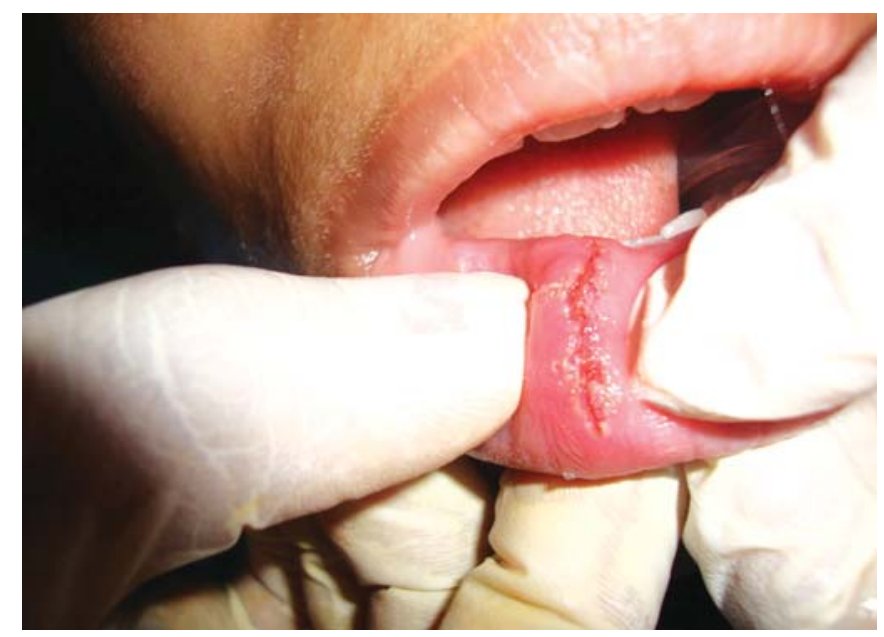

Fig. 17: Tissue approximation (case 2)

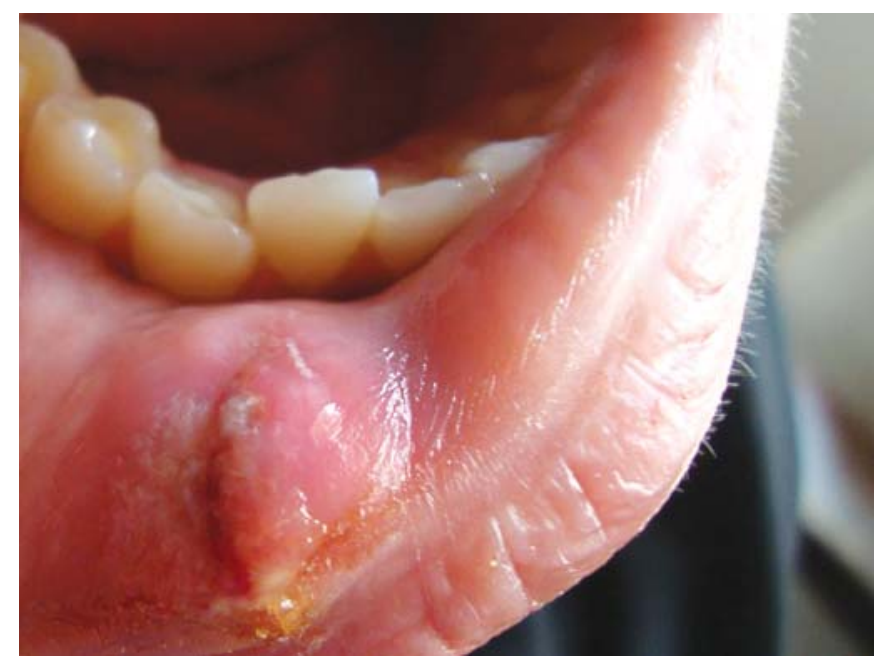

Fig. 18: One-day postoperative view (case 2) 
convenient for the fast paced life of patients by reducing the chairside time, recall and postoperative care.

\section{REFERENCES}

1. Khandelwal S, Patil S. Oral mucoceles - review of the literature. Minerva Stomatol 2012 Mar;61(3):91-99.

2. Seo J, Bruno I, Artico G, Vechio AD, Migliari DA. Oral mucocele of unusual size on the buccal mucosa: Clinical presentation and surgical approach. Open Dent J 2012;6:67-68.

3. Chawla K, Lamba AK, Faraz F, Tandon S, Arora S, Gupta M. Treatment of lower lip mucocele with Er,Cr:YSGG laser -a case report. J Oral Laser Applications 2010;10(4):181-85.

\section{ABOUT THE AUTHORS}

\section{Vidyaa Hari lyer (Corresponding Author)}

Private Practitioner, Smile Dental Clinic, Chennai, Tamil Nadu, India e-mail: vidyaahari@gmail.com

\section{Vijayalakshmi Moorthy}

Senior Lecturer, Department of Periodontics, Sathyabama University Dental College and Hospital, Chennai, Tamil Nadu, India

\section{Padmapriya Ramalingam}

Private Practitioner, Smile Dental Clinic, Chennai, Tamil Nadu, India 